Review began 01/27/2022 Review ended 02/01/2022 Published 02/05/2022

๑) Copyright 2022

Pan et al. This is an open access article distributed under the terms of the Creative Commons Attribution License CC-BY 4.0. which permits unrestricted use, distribution, and reproduction in any medium, provided the original author and source are credited.

\section{Meta-Analysis of Positive Psychology Interventions on the Treatment of Depression}

\author{
Shannon Pan ${ }^{1}$, Kiran Ali ${ }^{1}$, Chanaka Kahathuduwa ${ }^{1}$, Regina Baronia ${ }^{1}$, Yasin Ibrahim ${ }^{1}$ \\ 1. Psychiatry, Texas Tech University Health Sciences Center, Lubbock, USA
}

Corresponding author: Shannon Pan, shannon.a.pan@gmail.com

\begin{abstract}
This meta-analysis examined the efficacy of positive psychology interventions (PPIs) in treating depression in 11 articles. PubMed, Web of Science, and Clinical Key were used to identify papers published from 2010 to 2020 that utilized PPIs. Key terms were "positive psychology” and “treatment of depression.” Studies on adults with (a) depressive symptoms or (b) diagnosed clinical depression were included. A random-effects model was used to compare PPIs and control groups on post- vs. pre-intervention differences in depression scores. Data analysis examined Beck Depression Inventory-II (BDI-II), Center for Epidemiologic Studies Depression Scale (CES-D), and Quick Inventory of Depressive Symptomatology-Self-Report (QIDS-SR16) scores. Findings show PPIs are effective in treating depressive symptoms, with significant improvements in depression scores when compared to control groups in all but one study. This was true for both post- vs. preintervention (pooled Cohen's $\mathrm{d}=-0.44(-0.77,-0.11)$ ) and follow-up- vs. pre-intervention analyses (pooled Cohen's $d=-0.46(-1.02,0.09))$. PPIs can improve the accessibility and affordability of depression treatments.
\end{abstract}

Categories: Psychiatry, Psychology, Public Health

Keywords: well-being, optimism, gratitude, psychotherapy, treatment of depression, depression, positive psychology

\section{Introduction And Background}

Depression is a global crisis. The World Health Organization estimates that a staggering $264+$ million people suffer from depression, and with this comes the enormous social, economic, and systemic burdens that societies must face [1]. While medication can be effective in lessening acute symptoms, more long-term solutions require extensive psychotherapy so individuals can learn healthy and sustainable coping mechanisms [2].

There is a range of psychotherapy techniques that are used to treat depression, such as cognitive-behavioral therapy (CBT), interpersonal therapy (IPT), and third-wave cognitive and behavior therapies such as dialectical behavioral therapy (DBT) and acceptance and commitment therapy (ACT) [3,4]. More recently, positive psychotherapy (PPT) has gained increased attention as a possible treatment modality.

\section{Positive psychology terminology}

Positive psychology is an umbrella term that encompasses a wide range of humanistic theories and principles [5]. There is no singular definition, but its origins are from Martin Seligman, President of the American Psychological Association in 1998 and pillar of the positive psychology movement [5]. Prior to this movement, the main focus of mental health treatments was on the pathology of negative symptoms, and most of the efforts were channeled toward reducing these symptoms [6]. However, Seligman encouraged a more holistic approach to treating psychopathology - he emphasized the importance of focusing on positive aspects of life, such as love, gratitude, social ties, humor, and resilience (Figure 1) [7,8]. 


\section{Cureus}
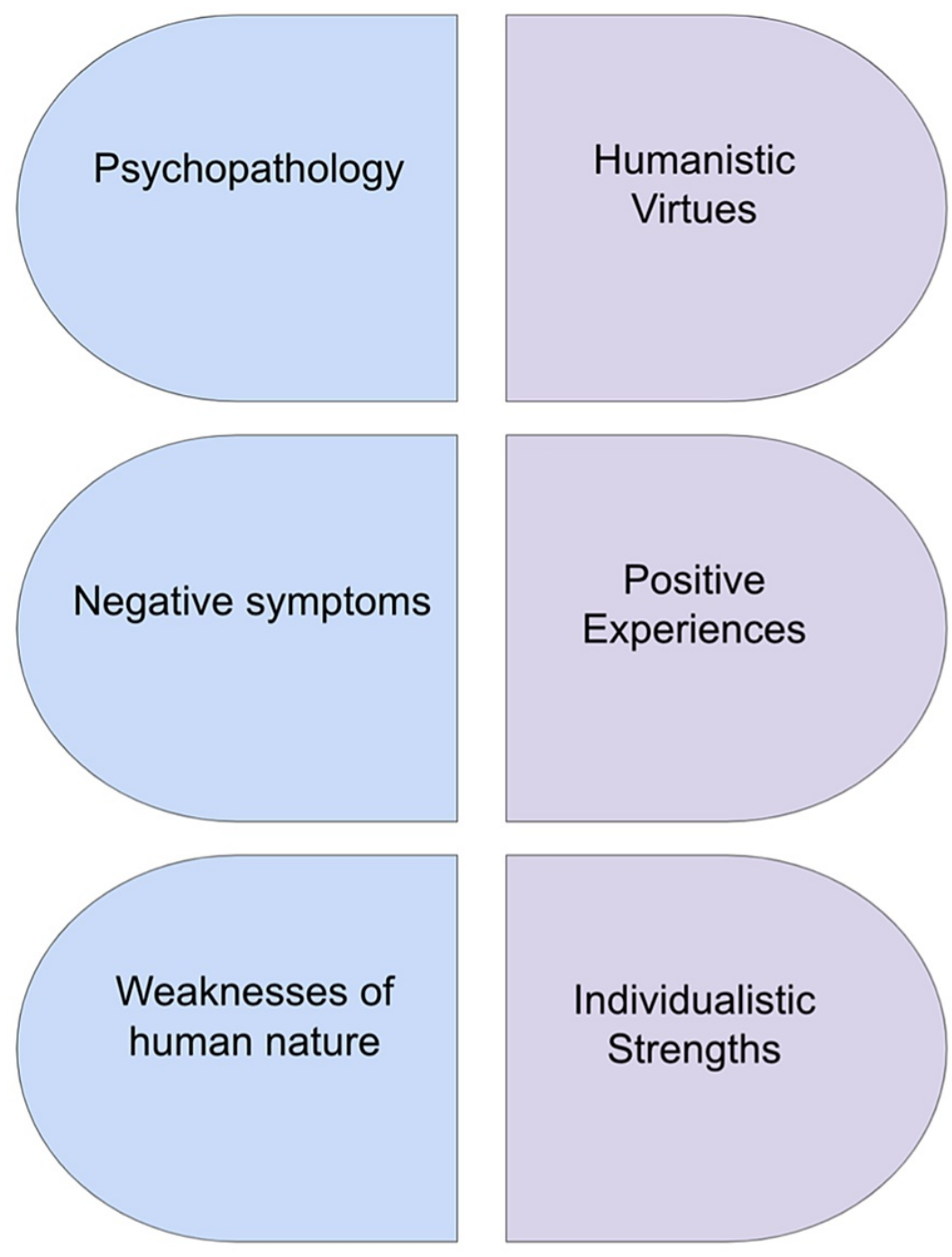

FIGURE 1: Balance of views.

Positive psychology provides a balance to the previous views of psychology; it gives reasons that make life worth living and fulfilling. Life consists of both suffering and joy, and positive psychology serves as a reminder that the focus should not be one-sided.

Positive psychology interventions (PPIs) can be categorized into six core domains: acts of kindness, gratitude, positive processing of past and present events, positive processing of future events, goal pursuit, and strength identification [9]. Each core domain is represented by an intervention (see Figure 2). While there are many more subdomains, the overall goal of these domains is to help individuals find meaning and purpose in their lives based on their own unique strengths [10]. This aligns with Seligman's theory on what constitutes authentic happiness, which includes positive emotions, engagement, and meaning (as seen in Figure 3) [5]. 


\section{Cureus}

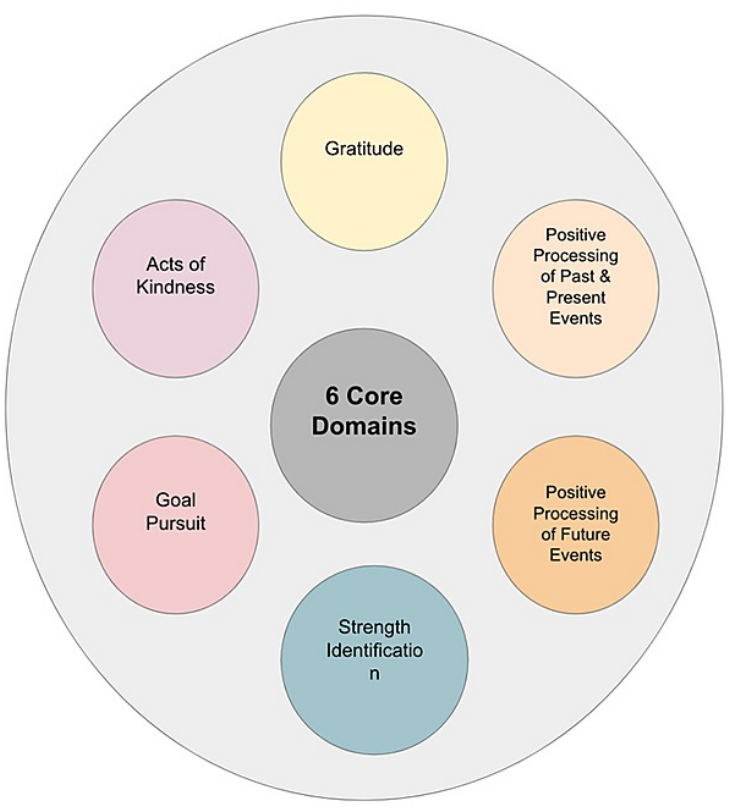

$$
\begin{aligned}
& \text { Listing personal gratitudes, } \\
& \text { expressing gratitude to others } \\
& \begin{array}{l}
\text { Positive self-statements, } \\
\text { humorous event listing and } \\
\text { causal analysis, hope-based } \\
\text { cognitive restructuring }
\end{array} \\
& \text { Optimism and planning } \\
& \text { Using strengths in a new way, } \\
& \text { cognitive restructuring } \\
& \text { Action coaching with } \\
& \text { self-monitoring and error } \\
& \text { correction, values clarification, } \\
& \text { hope visualization }
\end{aligned}
$$

\section{FIGURE 2: Six core domains of positive psychology.}

A color-coded diagram of the six core domains of positive psychology. Adapted from the topographical map by Gorlin et al. [9]. The subdomains on the left represent more specific examples and activities that are commonly used in positive psychology interventions.

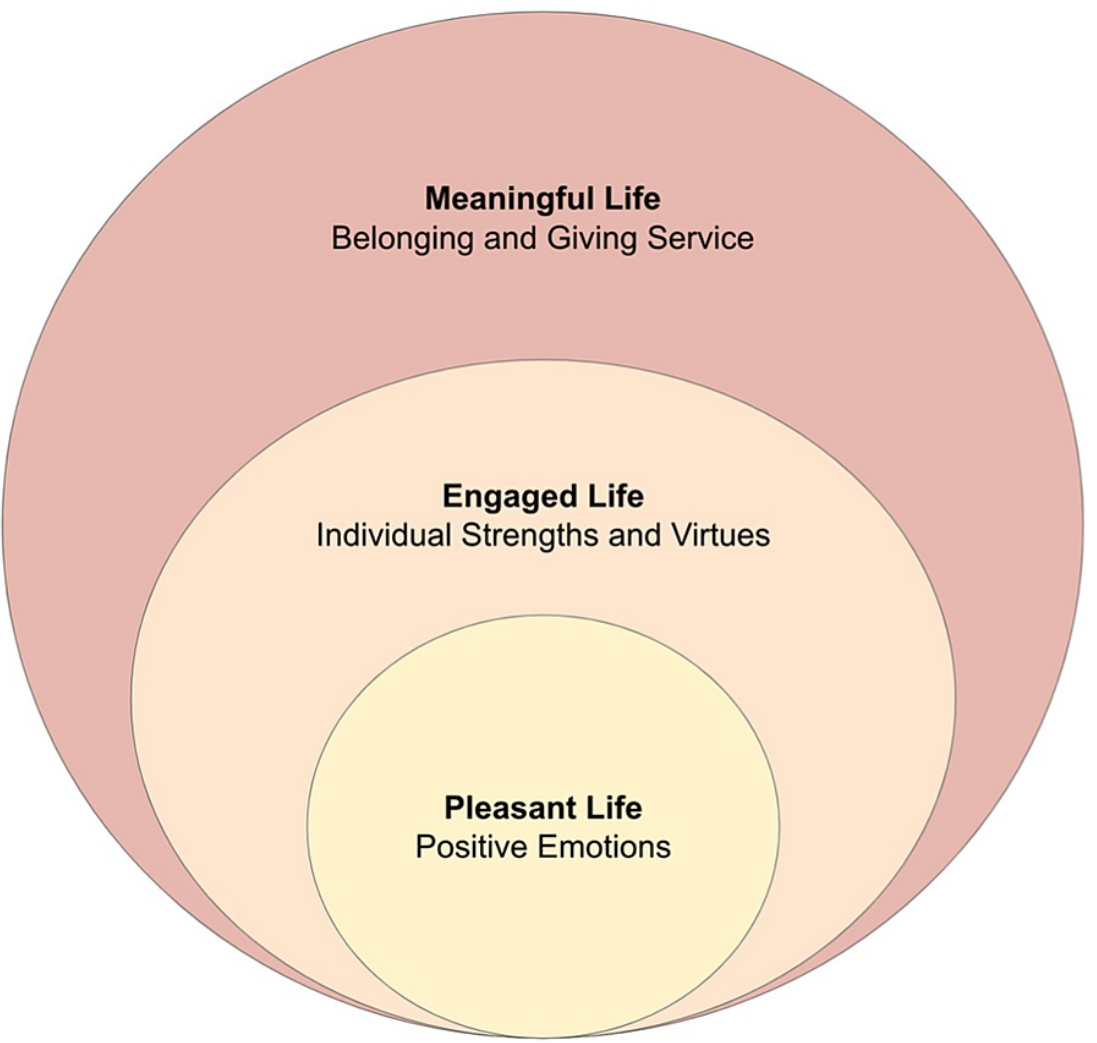

FIGURE 3: Theory of authentic happiness.

A diagram based on the three components of a good life as described in Schrank et al. [5]. This illustrates how Seligman's theory on authentic happiness spans across many domains in an individual's life, ranging from a more personal to a societal level. As depicted, happiness tends to radiate outwards when it starts from within. 
PPIs aim to improve well-being at not only the individual level but at the societal and interpersonal levels as well [5]. Although research showing empirical evidence of the efficacy of PPI is still recent, there have already been many studies that show PPIs are effective in combating symptoms of depression, such as suicidality and hopelessness [11-13].

PPT is the psychotherapy technique that emerged from the movement and represents a combination of evidence-based interventions combined into a single intervention manual [5]. PPT allows for a more uniform way of delivering PPT exercises to patients, and since it was originally developed for people with depressive symptoms, it serves as a promising intervention for more serious disorders such as depression [5]. A distinguishing feature of PPT, compared with other psychotherapy techniques, such as CBT, is its emphasis on fostering traits unique to each individual that allow them to live an optimal life [14-16]. Patients are encouraged to practice mindfulness and awareness, and in doing so, they can increase selfawareness, positive emotions, and ultimately well-being $[17,18]$.

\section{Purpose of study}

The purpose of this study was to systematically analyze the effects of PPI on the treatment of depression in adults and the elderly. Studies within the last 10 years that utilize PPIs on patients with depression or depressive symptoms were examined. This meta-analysis will provide researchers with empirical evidence of the intervention's benefits, specifically its therapeutic value, cost-effectiveness, and longitudinal benefits. We hypothesized that PPIs would effectively treat depression or alleviate depressive symptoms when compared to control groups.

\section{Review}

\section{Methods}

Search Strategy and Eligibility Screening

Three databases, PubMed, Web of Science, and Clinical Key, were used to identify papers published from 2010 to 2020, and hand searches were also conducted after the systematic searches. The key terms used for each database were "positive psychology" and "treatment of depression."

Only studies with a patient population of adults aged $18+$ years with either (a) depressive symptoms or (b) diagnosed clinical depression were included in the analysis. Studies were included if a PPI was used. There were restrictions on study design and outcome measurement. This paper does not include positive intervention in conjunction with already-proven psychotherapies such as CBT and meditation. Studies that included psychopharmacological intervention were included if both of intervention group and control group received the same medication. Opinion pieces such as editorials, abstracts, and letters to the editor were not included. These exclusion criteria were applied during the title and abstract screening process. Papers were all published in English (Figure 4). 


\section{Cureus}

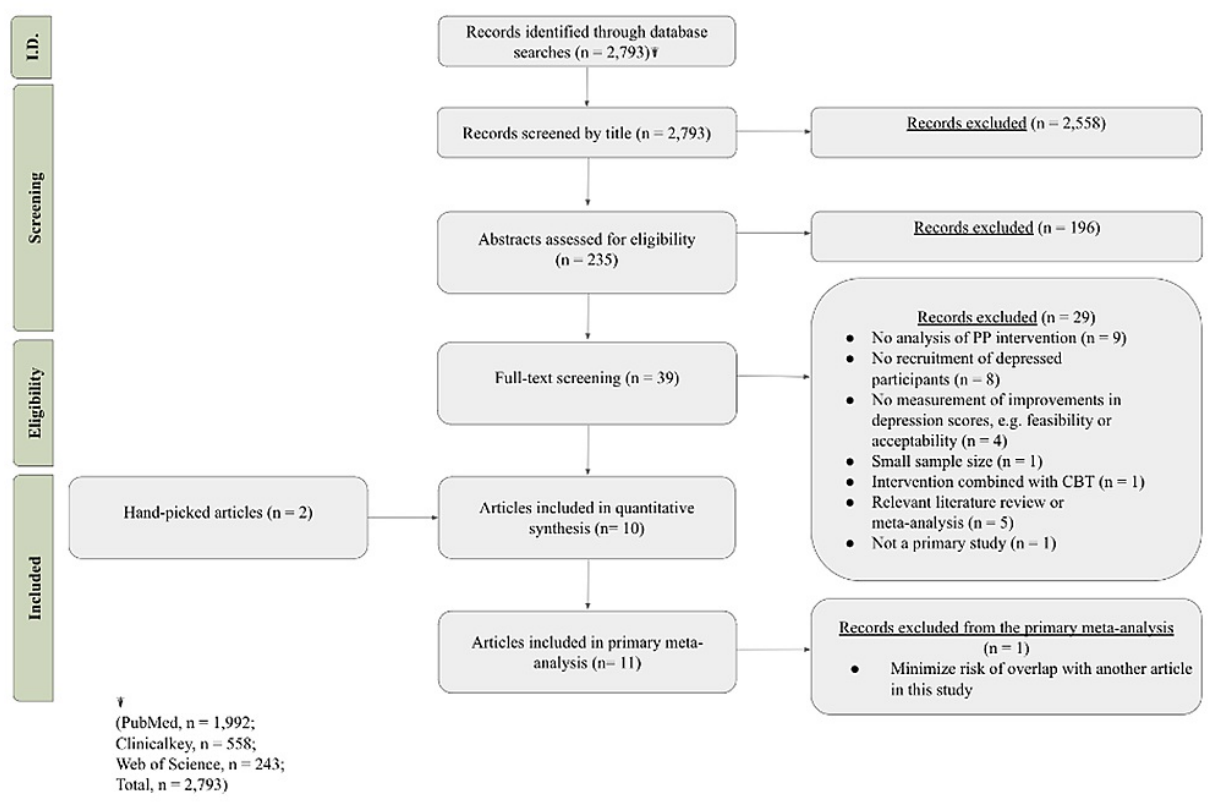

\section{FIGURE 4: Flow diagram.}

I.D.: identification phase; PP: positive psychology; $C B T$ : cognitive-behavioral therapy.

Data Extraction

Data were extracted from the eligible manuscripts into pre-defined data fields. Sample size, the scale used to measure depression symptoms/severity, mean post- vs. pre-intervention change of depression scores, and standard deviation of post- vs. pre-intervention change of depression scores of interventions (i.e., positive psychology) and control groups were extracted from the eligible full-text articles. When only the standard deviations of marginal means were available, the standard deviations of mean differences were imputed using the methods described in the Cochrane Handbook [19]. In addition, the following data of the intervention group were extracted as potential covariates of the above outcomes: mean age of participants, the proportion of females, the proportion of participants who received $>12$ years of education, the proportion of participants who were employed, and the proportion of participants who had a partner/were married. Furthermore, the year of publication and duration of intervention were extracted as potential covariates. When the articles reported outcomes of delayed follow-up following an intervention, the followup vs. pre-intervention change of depression scores and standard deviation of post- vs. pre-intervention change of depression scores of interventions (i.e., positive psychology) and control groups were extracted. The duration of follow-up was also extracted from these articles as an additional covariate.

Data Analysis

Two separate DerSimonian-Laird random-effects meta-analyses were performed using the "meta" package (version 4.11-0) in R statistical software (version 3.6.2; R Foundation for Statistical Computing, Vienna, Austria) to examine standardized intervention vs. control group differences in (a) post- vs. pre-intervention changes and (b) post-follow-up vs. pre-intervention changes of depression scores [20]. Additional subgroup analyses were conducted to examine these differences based on the instruments used to measure depression (e.g. Beck Depression Inventory-II (BDI-II) and Center for Epidemiologic Studies Depression Scale (CES-D)). The consistency of the findings of the meta-analyses was confirmed by leave-one-out sensitivity analyses [21]. Given that under-reporting and publication bias could result in biased (i.e., smaller) estimates, publication bias was examined using funnel plots and with the aim of imputing effect sizes of missing (i.e., unpublished/unreported) studies via the trim-and-fill method [22,23]. Heterogeneity of effect sizes was quantified by calculating the Higgins' I2 statistic [24,25]. To explain the heterogeneity of the studies, exploratory univariate random-effects meta-regression analyses were performed to examine the moderator effects of each of the covariates described above [26].

\section{Results}

Initial Search Results

The title search on PubMed, Clinical Key, and Web of Science yielded 235 articles after excluding those that did not mention positive psychology or depression. The abstract screen yielded 39 articles after excluding articles that did not use PPI. Full texts were assessed and reviewed individually, yielding 10 articles (see 


\section{Cureus}

Figure 4 for a breakdown). A secondary search was conducted through relevant literature reviews and metaanalyses, and two articles were included in this study as hand-picked articles. During the primary metaanalysis step, one article was eliminated to minimize overlap due to similarity in protocol and results, which did not significantly change the pooled prevalence estimate. There were 11 total articles assessed in the final meta-analysis [12,27-36].

Critical Appraisal

The quality assessment included whether the article was peer-reviewed, was a randomized controlled trial, double-blinded, or included a follow-up (Table 1).

\begin{tabular}{|c|c|c|c|c|c|}
\hline Article & Blinded & Peer-reviewed & Randomized & Follow-up & Control condition \\
\hline 1. Bolier et al. (2013) [27] & & $\checkmark$ & $\checkmark$ & $\checkmark$ & $\checkmark$ \\
\hline 2. Chaves et al. (2017) [28] & $\checkmark$ & $\checkmark$ & & & $\checkmark$ \\
\hline 3. Ducasse et al. (2018) [12] & $\checkmark$ & $\checkmark$ & $\checkmark$ & & $\checkmark$ \\
\hline 4. Furchtlehner et al. (2019) [29] & & $\checkmark$ & $\checkmark$ & $\checkmark$ & $\checkmark$ \\
\hline 5. Guo et al. (2017) [30] & & $\checkmark$ & $\checkmark$ & $\checkmark$ & $\checkmark$ \\
\hline 6. Hanson (2019) [31] & & $\checkmark$ & $\checkmark$ & $\checkmark$ & $\checkmark$ \\
\hline 7. Proyer et al. (2014) [32] & & $\checkmark$ & $\checkmark$ & $\checkmark$ & $\checkmark$ \\
\hline 8. Ramirez et al. (2014) [33] & & $\checkmark$ & $\checkmark$ & $\checkmark$ & $\checkmark$ \\
\hline 9. Asgharipoor et al. (2012) [34] & & $\checkmark$ & $\checkmark$ & & $\checkmark$ \\
\hline 10. Silton et al. (2020) [35] & & $\checkmark$ & & $\checkmark$ & \\
\hline 11. Celano et al. (2017) [36] & $\checkmark$ & $\checkmark$ & $\checkmark$ & $\checkmark$ & $\checkmark$ \\
\hline
\end{tabular}

TABLE 1: Quality assessment.

Results From the Literature

Table 2 summarizes the 11 articles analyzed in this study. Collectively, 736 participants were in the PPI group and 615 participants were in various control groups. There were three main categories of PPIs among the 11 studies, and they included internet-based interventions (2), group positive psychotherapy (5), and individual reflection or self-help (3). A majority of the group therapy interventions were weekly and also included homework and exercises between sessions.

\begin{tabular}{|c|c|c|c|c|c|c|c|c|}
\hline Study & Country & Delivery & $\begin{array}{l}\text { Sessions, } \\
\text { duration }\end{array}$ & $\mathbf{N}$ & $\begin{array}{l}\text { Clinical } \\
\text { status }\end{array}$ & $\begin{array}{l}\text { Age } \\
\text { range }\end{array}$ & $\begin{array}{l}\text { Control } \\
\text { group }\end{array}$ & Findings \\
\hline $\begin{array}{l}\text { 1. Bolier et } \\
\text { al. }(2013) \\
{[27]}\end{array}$ & Netherlands & $\begin{array}{l}\text { Psyfit, internet-based } \\
\text { intervention, personal } \\
\text { training program }\end{array}$ & $\begin{array}{l}6 \text { modules, } \\
2 \text { months }\end{array}$ & 143 & $\begin{array}{l}\text { Mild to } \\
\text { moderate } \\
\text { depression } \\
\text { (CES-D) }\end{array}$ & $\begin{array}{l}\text { Mean: } \\
43.5\end{array}$ & Waiting list & $\begin{array}{l}\text { Significant improvement }(\mathrm{p}= \\
0.049 \text { ) in overall well-being with } \\
\text { intervention according to WHO-5 } \\
\text { measurement for two-month } \\
\text { follow-up }\end{array}$ \\
\hline $\begin{array}{l}\text { 2. Chaves et } \\
\text { al. (2017) } \\
\text { [28] }\end{array}$ & Spain & $\begin{array}{l}\text { In-person group } \\
\text { psychotherapy with a } \\
\text { licensed therapist }\end{array}$ & $\begin{array}{l}\text { Weekly 2- } \\
\text { hour } \\
\text { sessions, } \\
10 \text { weeks }\end{array}$ & 47 & $\begin{array}{l}\text { Women with } \\
\text { major } \\
\text { depression } \\
\text { or dysthymia } \\
\text { (DSM-IV, } \\
\text { SCID) }\end{array}$ & $\begin{array}{l}\text { Mean: } \\
52.57\end{array}$ & CBT & $\begin{array}{l}\mathrm{CBT} \text { and } \mathrm{PPI} \text { are equally effective } \\
\text { in treating depressive symptoms } \\
(p=0.84)\end{array}$ \\
\hline $\begin{array}{l}\text { 3. Ducasse } \\
\text { et al. (2019) } \\
\text { [12] }\end{array}$ & France & $\begin{array}{l}\text { Gratitude diary with } \\
\text { individual reflection }\end{array}$ & 7 days & 101 & $\begin{array}{l}\text { Patients } \\
\text { hospitalized } \\
\text { with MDD } \\
\text { and suicide } \\
\text { ideations (C- }\end{array}$ & $18-65$ & Food diary & $\begin{array}{l}\text { PPI significantly improved levels } \\
\text { of depression in comparison to } \\
\text { the control group ( } p=0.008 \text { ). } \\
\text { Gratitude was associated with }\end{array}$ \\
\hline
\end{tabular}




\section{Cureus}

\begin{tabular}{|c|c|c|c|c|c|c|c|c|}
\hline & & & & & SSRS) & & & improved optimism \\
\hline $\begin{array}{l}4 . \\
\text { Furchtlehner } \\
\text { et al. (2019) } \\
\text { [29] }\end{array}$ & Austria & $\begin{array}{l}\text { Group psychotherapy } \\
\text { with a licensed } \\
\text { therapist using the } \\
\text { PERMA model }\end{array}$ & 14 weeks & 46 & $\begin{array}{l}\text { Depressive } \\
\text { disorder } \\
\text { (DMS-IV) }\end{array}$ & $18-60$ & CBT & $\begin{array}{l}\text { PP patients demonstrated fewer } \\
\text { depressive symptoms over six } \\
\text { months compared to CBT } \\
\text { patients }(p<0.001)\end{array}$ \\
\hline $\begin{array}{l}\text { 5. Guo et al. } \\
\text { (2017) [30] }\end{array}$ & Australia & $\begin{array}{l}\text { Group psychotherapy } \\
\text { with eight exercises }\end{array}$ & $\begin{array}{l}1.5 \text { hours } \\
\text { discussion } \\
\text { and } 1- \\
\text { week } \\
\text { practice } \\
\text { per } \\
\text { exercise, } 8 \\
\text { weeks }\end{array}$ & 42 & $\begin{array}{l}\text { Nursing } \\
\text { students with } \\
\text { mild- } \\
\text { moderate } \\
\text { depression } \\
\text { (BDI-II) }\end{array}$ & $\begin{array}{l}\text { Mean: } \\
20.39\end{array}$ & $\begin{array}{l}\text { School } \\
\text { routine help } \\
\text { (once a } \\
\text { semester } \\
\text { psychological } \\
\text { counseling) }\end{array}$ & $\begin{array}{l}\text { The intervention significantly } \\
\text { alleviated depression }(p=0.0001) \\
\text { with significantly lower scores } \\
\text { than the control group. PPT } \\
\text { cultivated positive thoughts and } \\
\text { behavior, which is associated } \\
\text { with less depressive symptoms }\end{array}$ \\
\hline $\begin{array}{l}\text { 6. Hanson } \\
\text { (2019) [31] }\end{array}$ & England & $\begin{array}{l}\text { PP self-help book titled } \\
\text { positive psychology for } \\
\text { overcoming depression }\end{array}$ & 8 weeks & 16 & $\begin{array}{l}\text { Depressive } \\
\text { symptoms } \\
\text { not receiving } \\
\text { treatment }\end{array}$ & $19-69$ & $\begin{array}{l}\text { CBT self- } \\
\text { help book }\end{array}$ & $\begin{array}{l}\text { There is no statistical difference } \\
(p=0.5) \text { in PP and CBT self-help } \\
\text { books, but bibliotherapy is a cost- } \\
\text { effective method to alleviate } \\
\text { depressive symptoms }\end{array}$ \\
\hline $\begin{array}{l}\text { 7. Proyer et } \\
\text { al. (2014) } \\
\text { [32] }\end{array}$ & Switzerland & $\begin{array}{l}\text { Four online and self- } \\
\text { administered } \\
\text { exercises: gratitude } \\
\text { visit, three good things, } \\
\text { using signature } \\
\text { strengths, three funny } \\
\text { things }\end{array}$ & 1 week & 163 & $\begin{array}{l}\text { Depressive } \\
\text { symptoms }\end{array}$ & $50-70$ & $\begin{array}{l}\text { Early } \\
\text { memories }\end{array}$ & $\begin{array}{l}\text { Three interventions (gratitude } \\
\text { visit, three good things, and } \\
\text { signature strengths) statistically } \\
\text { increased happiness, and two } \\
\text { interventions (three funny things } \\
\text { and signature strengths) reduced } \\
\text { depressive symptoms }\end{array}$ \\
\hline $\begin{array}{l}\text { 8. Ramirez } \\
\text { et al. (2014) } \\
\text { [33] }\end{array}$ & Spain & $\begin{array}{l}\text { Group psychotherapy } \\
\text { with homework via } \\
\text { MAPEG program }\end{array}$ & $\begin{array}{l}1.5 \text { hour } \\
\text { sessions } \\
\text { per week, } \\
9 \text { weeks }\end{array}$ & 26 & $\begin{array}{l}\text { Depressive } \\
\text { symptoms }\end{array}$ & $60-93$ & $\begin{array}{l}\text { Placebo } \\
\text { (early } \\
\text { memories) }\end{array}$ & $\begin{array}{l}\text { The experimental group } \\
\text { demonstrated a significant } \\
\text { decrease in state anxiety and } \\
\text { depression as well as an } \\
\text { increase in specific memories, life } \\
\text { satisfaction, and subjective } \\
\text { happiness, compared with the } \\
\text { placebo group ( } p<0.04)\end{array}$ \\
\hline $\begin{array}{l}9 . \\
\text { Asgharipoor } \\
\text { et al. (2012) } \\
\text { [34] }\end{array}$ & Iran & $\begin{array}{l}\text { Group psychotherapy } \\
\text { with citalopram } \\
\text { medication }(20-40 \mathrm{mg})\end{array}$ & 12 weeks & 9 & MDD & $\begin{array}{l}\text { Mean: } \\
36\end{array}$ & $\begin{array}{l}\text { Group CBT } \\
\text { with } \\
\text { citalopram } \\
\text { medication } \\
(20-40 \mathrm{mg})\end{array}$ & $\begin{array}{l}\text { PPI is more effective in } \\
\text { increasing happiness in MMD } \\
\text { patients than CBT }\end{array}$ \\
\hline $\begin{array}{l}\text { 10. Silton et } \\
\text { al. (2020) } \\
\text { [35] }\end{array}$ & USA & $\begin{array}{l}\text { Savoring intervention } \\
\text { with individual } \\
\text { reflection }\end{array}$ & 1 week & 111 & $\begin{array}{l}\text { Depressive } \\
\text { symptoms }\end{array}$ & $\begin{array}{l}\text { Mean: } \\
70.7\end{array}$ & None & $\begin{array}{l}\text { PPI was successful at reducing } \\
\text { depressive symptoms in those } \\
\text { participants with high fidelity }\end{array}$ \\
\hline $\begin{array}{l}\text { 11. Celano } \\
\text { et al. (2017) } \\
\text { [36] }\end{array}$ & USA & $\begin{array}{l}\text { HOPE, treatment } \\
\text { manual with PP } \\
\text { exercises and weekly } \\
\text { one-on-one telephone } \\
\text { sessions }\end{array}$ & 6 weeks & 32 & $\begin{array}{l}\text { Patients with } \\
\text { MDD } \\
\text { recently } \\
\text { hospitalized } \\
\text { for suicidal } \\
\text { ideation or } \\
\text { attempt } \\
\text { (MINI) }\end{array}$ & $\begin{array}{l}\text { Mean: } \\
43.2\end{array}$ & $\begin{array}{l}\text { Cognition- } \\
\text { focused } \\
\text { intervention }\end{array}$ & $\begin{array}{l}\text { PPI was successful at increasing } \\
\text { optimism and gratitude and } \\
\text { decreasing suicide ideation and } \\
\text { depression. However, it was not } \\
\text { superior to the CF control }\end{array}$ \\
\hline
\end{tabular}

\section{TABLE 2: Summary of studies included.}

CES-D: Center for Epidemiologic Studies Depression Scale; DSM-IV: Diagnostic and Statistical Manual of Mental Disorders, Fourth Edition; SCID: Structured Clinical Interview for DSM Disorders; C-SSRS: Columbia Suicide Severity Rating Scale; MDD: major depressive disorder; MINI: Mini International Neuropsychiatric Interview; PP: positive psychology; CBT: cognitive-behavioral therapy; PPI: positive psychology intervention; CF: cognition-focused. 
In the random-effects meta-analysis that compared PPIs vs. control groups on post- vs. pre-intervention differences in depression scores, PPIs were observed to significantly decrease standardized depression scores compared to the controls (pooled Cohen's $d=-0.44(-0.77,-0.11)$ ) (Figure 5). Excluding any single study from the meta-analysis (i.e., leave-one-out sensitivity analyses) did not significantly change the pooled prevalence estimate. Subgroup analyses performed to examine the pooled post- vs. pre-intervention differences within the studies using BDI-II and CES-D also revealed significant pooled post- vs. preintervention differences (pooled Cohen's $d=-0.67(-1.20,-0.14)$ and pooled Cohen's $d=-0.30(-0.48$, -0.12), respectively). Only one study used Quick Inventory of Depressive Symptomatology-Self-Report (QIDS-SR16) and it showed a significant increase in depressive symptoms with PPI compared to the control intervention (Cohen's d $=0.57(0.07,1.06)$ ). Furthermore, the funnel plot of effect sizes was symmetrical, indicating publication bias seems to be less likely.

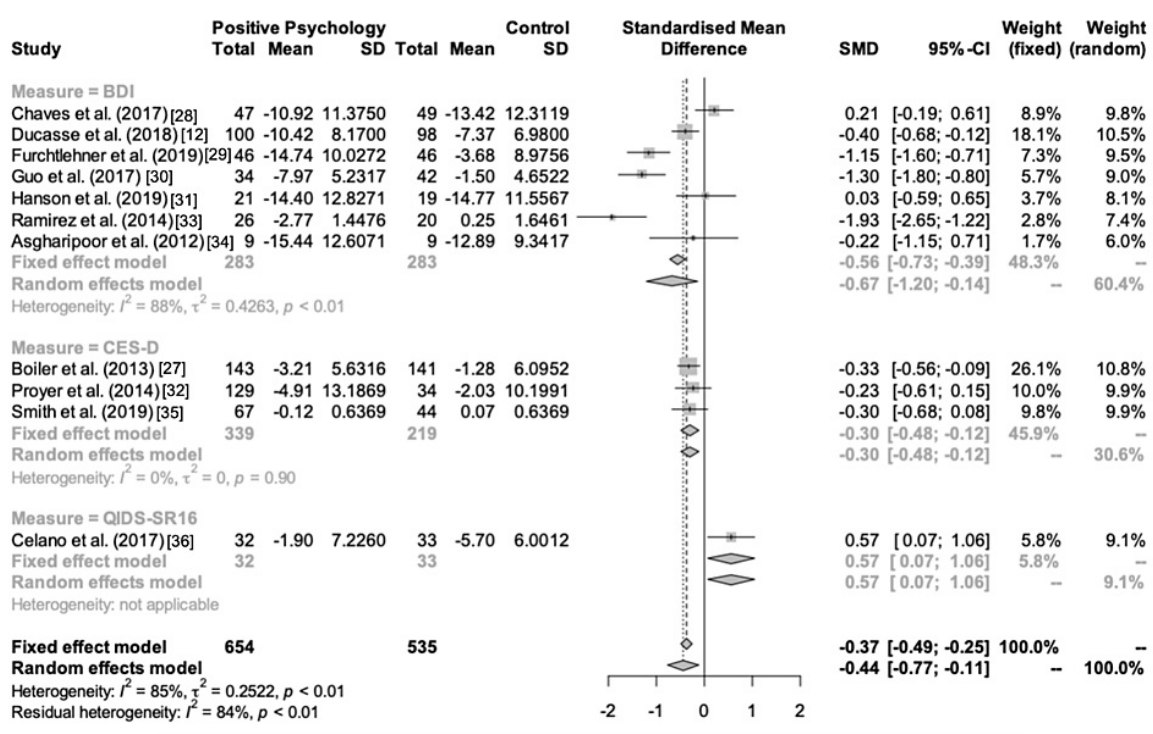

\section{FIGURE 5: Forest plot depicting differences in depression scores for post vs. pre-intervention for each study.}

Significant heterogeneity was observed among the mean differences pooled in the random-effects model ( $\tau 2$ $=0.252 ; \mathrm{I} 2=85.3 \% ; \mathrm{p}<0.001$ ). Exploratory univariate random-effects meta-regression analyses conducted with the aim of explaining the heterogeneity using the moderator effects of the considered covariates suggested the increased proportion of individuals engaged in higher education had a trend in decreasing the intervention effect $(\mathrm{p}=0.077)$ and the measure QIDS-SR16 was also associated with a significant decrease in the PPI effect $(\mathrm{p}=0.036)$. Yet, these covariates failed to significantly explain the heterogeneity of effect sizes. All other covariates did not show significant moderator effects on univariate meta-regression analyses $(\mathrm{p}>0.050)$. The combination of mean age, year of publication, the measure of depression, and the proportion involved in higher education collectively explained the $86.43 \%$ of residual heterogeneity $(\tau 2=$ $0.0019 ; \mathrm{I} 2=33.1 \% ; \mathrm{p}<0.002)$. In this model, mean age was a significant positive moderator $(\mathrm{p}=0.008)$, suggesting that increasing age was associated with a decreased intervention effect. The year of publication was a significant negative moderator $(\mathrm{p}=0.012)$, suggesting that the effectiveness of PPIs may have improved with time. The other two covariates did not have a significant moderator effect.

Follow-Up- vs. Pre-intervention Difference

In the random-effects meta-analysis that compared PPIs vs. control groups on post-follow-up- vs. preintervention differences in depression scores, PPIs were observed to decrease standardized depression scores compared to the controls (pooled Cohen's $d=-0.46(-1.02,0.09)$ ) (Figure 6 ); however, this reduction was not statistically significant. Leave-one-out sensitivity analyses revealed that excluding the Celano et al.'s [36] study from the meta-analysis reveals a significant treatment effect for PPI (Cohen's $d=-0.64(-1.21$, $-0.09), \mathrm{p}=0.0238$ ). Subgroup analyses performed to examine the pooled post- vs. pre-intervention differences within the studies using BDI-II and CES-D, however, did not reveal significant differences, possibly due to the limited number of studies in each group (pooled Cohen's $d=-1.10(-2.51,0.30)$ and pooled Cohen's $d=-0.26(-0.58,0.06)$, respectively). On the other hand, Celano et al. [36] showed a detrimental effect on depression symptoms with PPI compared to the control intervention (Cohen's $d=0.69$ $(0.18,1.19))$. Funnel plot of effect sizes was evident of potential publication bias, yet the trim-and-fill method failed to impute missing effect sizes. 


\section{Cureus}

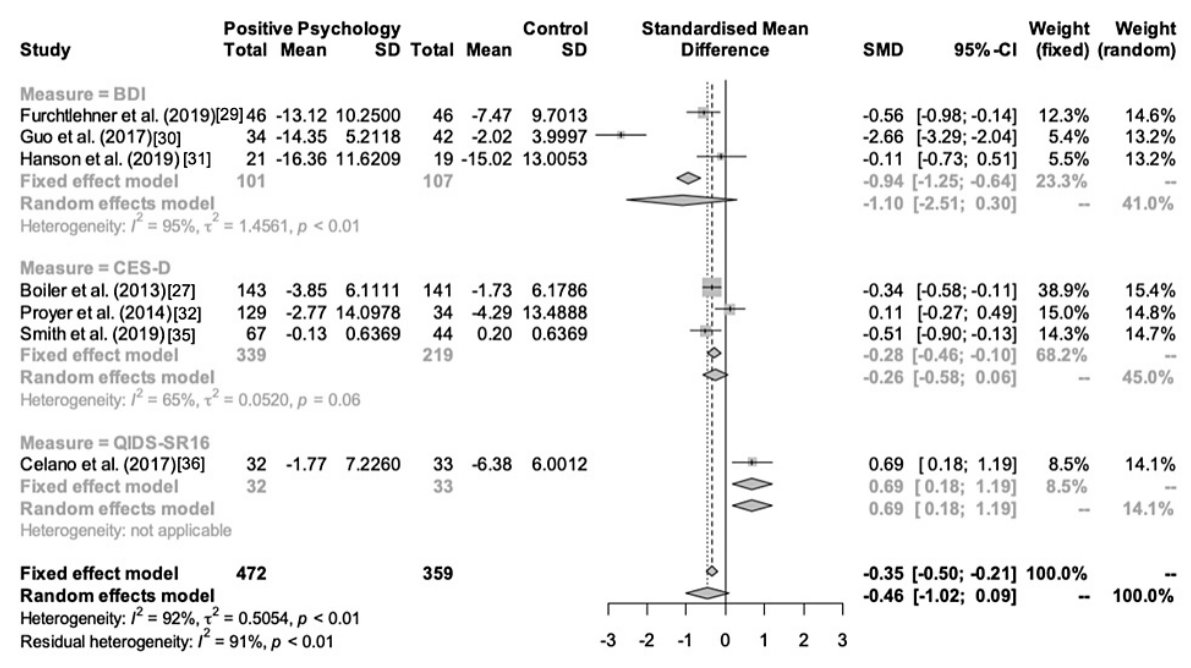

\section{FIGURE 6: Forest plot depicting differences in depression scores for follow-up vs. pre-intervention for each study.}

As in the previous meta-analysis, significant heterogeneity was a concern ( $\tau 2=0.505 ; \mathrm{I} 2=92.2 \% ; \mathrm{p}<0.001$ ). Exploratory univariate random-effects meta-regression analyses revealed a negative moderator effect of the proportion of individuals engaged in higher education $(p=0.011$ ), suggesting that the PPIs seem to be more effective for individuals who have received higher education. Yet, this covariate failed to significantly explain the heterogeneity. Mean age had a positive trend on the pooled standardized mean difference, suggesting that the effectiveness of the PPIs on depression seems to decrease with age. All other covariates did not show significant moderator effects on univariate meta-regression analyses $(p>0.050)$. The combination of the proportion involved in higher education and the depression scale fully explained the residual heterogeneity $(\tau 2=0.000 ; \mathrm{I} 2=0.0 \%, \mathrm{p}<0.001)$. In this model, the proportion that received higher education remained a significant negative moderator $(\mathrm{p}<0.001)$ and the CES-D scale (compared to the reference, BDIII) remained a significant positive moderator $(\mathrm{p}<0.001)$.

\section{Discussion}

Main Findings From the Literature

This study is the first meta-analysis conducted that analyzed the efficacy of PPIs on the treatment of depressive symptoms with high-quality studies. The results from pooling the effect sizes together in a random-effects model show that compared to a variety of different control groups, PPIs provided significantly decreased depression scores in both post-treatment and post-follow-up measures.

The study found significant heterogeneity for both the follow-up and pre-intervention groups, as well as in the pre- and post-intervention differences, which indicate that positive psychology worked very well in some studies and moderately well in others. The diversity in the methods and duration of PPIs used across the studies, ranging from weekly group therapy to daily self-journaling, accounts for the heterogeneity found in this meta-analysis. Apart from one study [36], all studies found PPIs to be more effective and beneficial in participants compared to the control. The participants in this study were acutely depressed and reported suicidal ideation or a recent suicide attempt. Due to the severity of their symptoms, this group of patients may have found it difficult to actively engage in positive psychology exercises. This suggests that positive psychology may not be suitable for higher-risk or severely depressed patients who are unable to actively engage in positive thoughts.

All but one of the 11 studies had a control group [35]; the control groups included a CBT intervention, placebos, and a waiting list. CBT has extensive empirical evidence and was used in control groups for half of the studies. An important finding was from Lopez-Gomez et al.'s study [37], where it was shown that patients who had positive psychology had much better outcomes than CBT treatment [37]. This implies that PPI is beneficial for most patients, and for patients who are not suited for other forms of psychotherapy, PPI may provide the optimal treatment. Further studies can inform which populations would optimally benefit from PPI.

\section{Analysis of the Covariates}

Multiple covariates, such as the proportion of females and education level, were analyzed to see whether or 
not they could explain the heterogeneity between the studies. The proportion of females in a study group and the proportion of individuals engaged in higher education were two covariates that increased the intervention effect, meaning that PPIs tend to work better for females and individuals with higher levels of education. While this is an association, and not causal, this is an important implication to keep in mind when assessing patients for mental health treatment options. Mean age was also found to be a significant positive moderator, and PPIs tended to work better for older individuals. For unclear reasons, older publications, regardless of intervention utilized, had greater effect sizes.

\section{Relevance to Clinical Practice}

This meta-analysis has important implications for clinical practice in treating depression as it clearly highlights the efficacy of PPI. Currently, the most utilized approach for treating depression is psychopharmacology with results being far from satisfactory. Psychotherapy, while considered first-line treatment, has time and monetary constraints. Resistant cases of depression are usually referred for repetitive transcranial magnetic stimulation (rTMS) and electroconvulsive therapy (ECT). Those treatments also have constraints in addition to being not available for many patients [38-41]. Thus, there is a need for alternative treatment options that are efficacious and accessible.

PPIs can be a valuable modality as a sole treatment as well as an adjunctive one. For example, in a metaanalysis conducted in 2018, 21 antidepressant drugs were tested on people with major depressive disorder (Cohen's $d=0.30$ ), and its pooled effect size was lower compared to this meta-analysis using positive psychology (Cohen's d = -0.54) [42]. CBT and PPI are often compared, and it has been shown that some people respond better to PPI whereas others show greater improvements with CBT. Since PPIs work well even when self-administered, there is less of a need for continuous physician support, which allows individuals to have long-term agency in maintaining their treatment.

The results from this study also have implications for primary care settings. Often, primary care physicians are the first to see psychological problems or co-morbidities in patients, which explains the description of primary care being the de facto mental health services system [43]. Not only is there an increasing demand for primary care physicians to handle mental health crises, but there is also a lag time between a primary care visit and a psychiatrist referral; studies show that less than one-third of mental health referrals are actually completed [44]. Because many PPIs are easily administered, and can even be self-administered, patients with less severe symptoms could be treated within a primary care setting without needing to be seen by a specialist. This makes mental health treatment more streamlined and it would better integrate physical and mental health maintenance with very little extra cost or energy investment [45].

Many of the interventions in this study were group positive psychotherapy. A potential reason for the popularity of group therapy is that it is more cost-effective than individual therapy, and individuals can learn from each other and the group dynamic. Online-administered modules and self-help interventions are even less costly, and they allow for more schedule flexibility for busy adults [31]. This way, mental health treatments can reach a broader audience. Additionally, with the rise in the popularity of telemedicine, there may be an increase in efforts to improve and develop internet-based interventions [46]. PPI is less commonly used in practice with healthcare providers, including psychiatrists, who generally do not get sufficient education, if any at all, on PPI during medical school or residency training [47]. Despite this challenge, there are existing methods for implementing PPI in clinic settings. For example, clinicians can use the Values in Action Inventory of Strengths (VIA-IS), which assesses a patient's top five strengths so that clinicians can help patients develop weekly goals to utilize these strengths [48]. This is just one of the many simple assessments described in a study by Slade; this study challenges clinicians to shift away from the emphasis on patient deficits and problems that most psychiatric histories focus on [48]. If patients are encouraged to pay more attention to worthy traits, they can have a more balanced and holistic view of themselves, which facilitates healing.

Criticisms of Positive Psychology

Critics of the positive psychology center their argument on the importance of knowing the limitations of positive psychology, the distinctiveness of the movement, and the ambiguous meaning of what is good [49]. It is important for patients undergoing therapy to recognize the limitations of positive psychology. Many critics of positive psychology claim that it serves to erase the negative realities of a situation, but that is not the approach taken by PPIs [50]. PPIs instead focus on building strength and resilience to help patients face their realities. It emphasizes a balanced mindset since it is difficult to stay optimistic while struggling with physical or mental illnesses. For example, patients with chronic diseases such as cancer or dementia may benefit from positive thinking but must also cope with their realities [18].

Many critics of positive psychology believe that if positive psychology exists, then the rest of the field should be considered negative psychiatry. In fact, psychology is mostly neutral but usually is centered around negative dilemmas $[49,51]$. One final critique is that due to the ambiguous nomenclature of what is good and positive, it is difficult to standardize study findings and draw conclusions about positive psychology's efficacy. Proponents of positive psychology believe that cultural norms or value systems can 
determine what is good.

Limitations

The studies included in this meta-analysis had limitations regarding sample size, study duration, and sample population heterogeneity. For example, three out of 11 of the studies had a sample size of less than 30 individuals $[31,33,34]$. Two of the 11 studies reported in this meta-analysis consisted of only women participants [28,32]. Furthermore, three of the 11 studies analyzed were only weeklong [12,32,35]. Outcomes of this meta-analysis could be potentially biased due to experimenter bias of individual studies. However, there is a statistically low publication bias in the field of positive psychology and therefore in this metaanalysis. Heterogeneity is expected in any meta-analysis because of variability in studies, and this metaanalysis was not resistant due to variability of methodology and study samples. Future studies should be held for a long duration, with larger sample size, and that study the general population more comprehensively. Finally, although this study focused on the effects of PPIs, the participants of some of these studies were also taking pharmacological intervention, which could play the part of a confounding variable in this study. However, we included studies where the pharmacologic agent was utilized in both the intervention and control groups.

\section{Future Directions}

Future directions to build on this study include finding the efficacy of PPI on different populations. For example, testing the efficacy of PPI in treating depression in adolescents could be an interesting find as this analysis only included studies with adult participants over the age of 18 years. More specific studies can also be done that address the efficacy of positive psychology on depressed patients from varied races, socioeconomic classes, education levels, and health statuses. While this study focused on treating depression and depressive symptoms, a future direction could be analyzing more severe mental disorders that could benefit from PPIs, such as schizophrenia or bipolar disorder. Expanding the possibilities would mean increasing the patient population that could benefit from these interventions.

\section{Conclusions}

This paper is the first meta-analysis on the efficacy of positive psychology on depression in the last five years. The results from this analysis show a promising future for the field of positive psychology and its plethora of interventions. This meta-analysis demonstrates positive psychology is efficacious in treating most patients with depression or depressive symptoms. With a focus on increasing individual well-being and agency, while not neglecting the negative aspects of mental illness, PPIs equip individuals with a balanced set of tools for coping with adversities in life. While there is still much to learn about the precise mechanisms and factors that it functions by, one thing is clear: people are benefiting from positive psychology and we should continue to advocate for its use and growth.

\section{Additional Information}

\section{Disclosures}

Conflicts of interest: In compliance with the ICMJE uniform disclosure form, all authors declare the following: Payment/services info: All authors have declared that no financial support was received from any organization for the submitted work. Financial relationships: All authors have declared that they have no financial relationships at present or within the previous three years with any organizations that might have an interest in the submitted work. Other relationships: All authors have declared that there are no other relationships or activities that could appear to have influenced the submitted work.

\section{References}

1. World Health Organization. Depression. (2020). Accessed: June 12, 2020: https://www.who.int/newsroom/fact-sheets/detail/depression.

2. Cuijpers P, Reynolds CF 3rd, Donker T, Li J, Andersson G, Beekman A: Personalized treatment of adult depression: medication, psychotherapy, or both? A systematic review. Depress Anxiety. 2012, 29:855-64. 10.1002/da.21985

3. Dunlop BW: Evidence-based applications of combination psychotherapy and pharmacotherapy for depression. Focus (Am Psychiatr Publ). 2016, 14:156-73. 10.1176/appi.focus.20150042

4. Hollon SD, Ponniah K: A review of empirically supported psychological therapies for mood disorders in adults. Depress Anxiety. 2010, 27:891-932. 10.1002/da.20741

5. Schrank B, Brownell T, Tylee A, Slade M: Positive psychology: an approach to supporting recovery in mental illness. East Asian Arch Psychiatry. 2014, 24:95-103.

6. Hasler G: Well-being: an important concept for psychotherapy and psychiatric neuroscience . Psychother Psychosom. 2016, 85:255-61. 10.1159/000447268

7. Seligman ME, Csikszentmihalyi M: Positive psychology. An introduction. Am Psychol. 2000, 55:5-14 10.1037//0003-066x.55.1.5

8. Alex Linley P, Joseph S, Harrington S, Wood AM: Positive psychology: past, present, and (possible) future. J Posit Psychol. 2006, 1:3-16. 10.1080/17439760500372796

9. Gorlin EI, Lee J, Otto MW: A topographical map approach to representing treatment efficacy: a focus on 
positive psychology interventions. Cogn Behav Ther. 2018, 47:34-42. 10.1080/16506073.2017.1342173

10. Duckworth AL, Steen TA, Seligman ME: Positive psychology in clinical practice. Annu Rev Clin Psychol. 2005, 1:629-51. 10.1146/annurev.clinpsy.1.102803.144154

11. Bränström R, Kvillemo P, Brandberg Y, Moskowitz JT: Self-report mindfulness as a mediator of psychological well-being in a stress reduction intervention for cancer patients-a randomized study. Ann Behav Med. 2010, 39:151-61. 10.1007/s12160-010-9168-6

12. Ducasse D, Dassa D, Courtet P, et al.: Gratitude diary for the management of suicidal inpatients: a randomized controlled trial. Depress Anxiety. 2019, 36:400-11. 10.1002/da.22877

13. Emmons RA, McCullough ME: Counting blessings versus burdens: an experimental investigation of gratitude and subjective well-being in daily life. J Pers Soc Psychol. 2003, 84:377-89. 10.1037//00223514.84.2.377

14. Phan HP, Ngu BH, Chen SC, et al.: Advancing the study of positive psychology: the use of a multifaceted structure of mindfulness for development. Front Psychol. 2020, 11:1602. 10.3389/fpsyg.2020.01602

15. Ciarrochi J, Atkins PW, Hayes LL, Sahdra BK, Parker P: Contextual positive psychology: policy recommendations for implementing positive psychology into schools. Front Psychol. 2016, 7:1561. 10.3389/fpsyg.2016.01561

16. Shoshani A, Slone M: Positive education for young children: effects of a positive psychology intervention for preschool children on subjective well being and learning behaviors. Front Psychol. 2017, 8:1866. 10.3389/fpsyg.2017.01866

17. Moskowitz JT, Addington EL, Cheung EO: Positive psychology and health: well-being interventions in the context of illness. Gen Hosp Psychiatry. 2019, 61:136-8. 10.1016/j.genhosppsych.2019.11.001

18. Park N, Peterson C, Szvarca D, Vander Molen RJ, Kim ES, Collon K: Positive psychology and physical health: research and applications. Am J Lifestyle Med. 2016, 10:200-6. 10.1177/1559827614550277

19. Higgins JP, Green S: Cochrane Handbook for Systematic Reviews of Interventions . John Wiley \& Sons, Chichester, UK; 2008.

20. DerSimonian R, Laird N: Meta-analysis in clinical trials. Control Clin Trials. 1986, 7:177-88. 10.1016/01972456(86)90046-2

21. Patsopoulos NA, Evangelou E, Ioannidis JP: Sensitivity of between-study heterogeneity in meta-analysis: proposed metrics and empirical evaluation. Int J Epidemiol. 2008, 37:1148-57. 10.1093/ije/dyn065

22. Duval S, Tweedie R: A nonparametric "trim and fill" method of accounting for publication bias in metaanalysis. J Am Stat Assoc. 2000, 95:89-98. 10.1080/01621459.2000.10473905

23. Duval S, Tweedie R: Trim and fill: a simple funnel-plot-based method of testing and adjusting for publication bias in meta-analysis. Biometrics. 2000, 56:455-63. 10.1111/j.0006-341x.2000.00455.x

24. Higgins JP, Thompson SG: Quantifying heterogeneity in a meta-analysis. Stat Med. 2002, 21:1539-58. 10.1002/sim. 1186

25. Higgins JPT: Cochrane Handbook for Systematic Reviews of Interventions Version 5.0.1 . Cochrane, London, UK; 2008.

26. Thompson SG, Sharp SJ: Explaining heterogeneity in meta-analysis: a comparison of methods . Stat Med. 1999, 18:2693-708. 10.1002/(sici)1097-0258(19991030)18:20<2693::aid-sim235>3.0.co;2-v

27. Bolier L, Haverman M, Kramer J, et al.: An internet-based intervention to promote mental fitness for mildly depressed adults: randomized controlled trial. J Med Internet Res. 2013, 15:e200. 10.2196/jmir.2603

28. Chaves C, Lopez-Gomez I, Hervas G, Vazquez C: A comparative study on the efficacy of a positive psychology intervention and a cognitive behavioral therapy for clinical depression. Cogn Ther Res. 2017, 41:417-33. 10.1007/s10608-016-9778-9

29. Furchtlehner LM, Schuster R, Laireiter AR: A comparative study of the efficacy of group positive psychotherapy and group cognitive behavioral therapy in the treatment of depressive disorders: a randomized controlled trial. J Posit Psychol. 2020, 15:832-45. 10.1080/17439760.2019.1663250

30. Guo YF, Zhang X, Plummer V, Lam L, Cross W, Zhang JP: Positive psychotherapy for depression and selfefficacy in undergraduate nursing students: a randomized, controlled trial. Int J Ment Health Nurs. 2017, 26:375-83. 10.1111/inm.12255

31. Hanson K: Positive psychology for overcoming symptoms of depression: a pilot study exploring the efficacy of a positive psychology self-help book versus a CBT self-help book. Behav Cogn Psychother. 2019, 47:95113. 10.1017/S1352465818000218

32. Proyer RT, Gander F, Wellenzohn S, Ruch W: Positive psychology interventions in people aged 50-79 years: long-term effects of placebo-controlled online interventions on well-being and depression. Aging Ment Health. 2014, 18:997-1005. 10.1080/13607863.2014.899978

33. Ramírez E, Ortega AR, Chamorro A, Colmenero JM: A program of positive intervention in the elderly: memories, gratitude and forgiveness. Aging Ment Health. 2014, 18:463-70. 10.1080/13607863.2013.856858

34. Asgharipoor N, Asgharnejad Farid A, Arshadi H, Sahebi A: A comparative study on the effectiveness of positive psychotherapy and group cognitive-behavioral therapy for the patients suffering from major depressive disorder. Iran J Psychiatry Behav Sci. 2012, 6:33-41.

35. Silton RL, Kahrilas IJ, Skymba HV, Smith J, Bryant FB, Heller W: Regulating positive emotions: implications for promoting well-being in individuals with depression. Emotion. 2020, 20:93-7. 10.1037/emo0000675

36. Celano CM, Beale EE, Mastromauro CA, et al.: Psychological interventions to reduce suicidality in high-risk patients with major depression: a randomized controlled trial. Psychol Med. 2017, 47:810-21. $10.1017 /$ S0033291716002798

37. Lopez-Gomez I, Chaves C, Hervas G, Vazquez C: Comparing the acceptability of a positive psychology intervention versus a cognitive behavioural therapy for clinical depression. Clin Psychol Psychother. 2017, 24:1029-39. 10.1002/cpp.2129

38. Zhang Z, Zhang L, Zhang G, Jin J, Zheng Z: The effect of CBT and its modifications for relapse prevention in major depressive disorder: a systematic review and meta-analysis. BMC Psychiatry. 2018, 18:50. 10.1186/s12888-018-1610-5

39. Wei Y, Zhu J, Pan S, Su H, Li H, Wang J: Meta-analysis of the efficacy and safety of repetitive transcranial magnetic stimulation (rTMS) in the treatment of depression. Shanghai Arch Psychiatry. 2017, 29:328-42. 


\section{Cureus}

40. Cuijpers P, Clignet F, van Meijel B, van Straten A, Li J, Andersson G: Psychological treatment of depression in inpatients: a systematic review and meta-analysis. Clin Psychol Rev. 2011, 31:353-60.

10.1016/j.cpr.2011.01.002

41. Abbass A, Gardner DM: Psychotherapy and medication options for depression. Am Fam Physician. 2004, 69:2071-4.

42. Cipriani A, Furukawa TA, Salanti G, et al.: Comparative efficacy and acceptability of 21 antidepressant drugs for the acute treatment of adults with major depressive disorder: a systematic review and network metaanalysis. Lancet. 2018, 391:1357-66. 10.1016/S0140-6736(17)32802-7

43. Regier DA, Goldberg ID, Taube CA: The de facto US mental health services system: a public health perspective. Arch Gen Psychiatry. 1978, 35:685-93. 10.1001/archpsyc.1978.01770300027002

44. Zeidler Schreiter EA, Pandhi N, Fondow MD, Thomas C, Vonk J, Reardon CL, Serrano N: Consulting psychiatry within an integrated primary care model. J Health Care Poor Underserved. 2013, 24:1522-30. 10.1353/hpu.2013.0178

45. Sin NL, Lyubomirsky S: Enhancing well-being and alleviating depressive symptoms with positive psychology interventions: a practice-friendly meta-analysis. J Clin Psychol. 2009, 65:467-87. 10.1002/jclp.20593

46. Norman S: The use of telemedicine in psychiatry . J Psychiatr Ment Health Nurs. 2006, 13:771-7. 10.1111/j.1365-2850.2006.01033.x

47. Kessler RC: The costs of depression. Psychiatr Clin North Am. 2012, 35:1-14. 10.1016/j.psc.2011.11.005

48. Slade M: Mental illness and well-being: the central importance of positive psychology and recovery approaches. BMC Health Serv Res. 2010, 10:26. 10.1186/1472-6963-10-26

49. Gable SL, Haidt J: What (and why) is positive psychology? . Rev Gen Psychol. 2005, 9:103-10. 10.1037/10892680.9.2.103

50. Lazarus RS: Does the positive psychology movement have legs?. Psychol Inq. 2003, 14:93-109. 10.1207/S15327965PLI1402_02

51. Wood AM, Tarrier N: Positive clinical psychology: a new vision and strategy for integrated research and practice. Clin Psychol Rev. 2010, 30:819-29. 10.1016/j.cpr.2010.06.003 